\title{
Functional evaluation of a new bioartificial liver system in vivo and in vivo
}

\author{
Zhong Chen, Yi-Tao Ding
}

Zhong Chen, Department of General Surgery, Affiliated Hospital, Nantong University, Nantong 226001, Jiangsu Province, China Yitao Ding, Department of Hepatobiliary Surgery, Affiliated Drum Tower Hospital, Medical School, Nanjing University, Nanjing 210008, Jiangsu Province, China

Supported by the Key Project Foundation of the Health Department of Jiangsu Province, China, No. BQ200020 and 2002 Qinglan Project Foundation of the Education Department of Jiangsu Province, China

Correspondence to: Zhong Chen, PhD, Department of General Surgery, Affiliated Hospital, Nantong University, Nantong 226001, Jiangsu Province, China. chenz_surg@sina.com.cn

Telephone: +86-513-5829806 Fax: +86-513-5106369

Received: 2005-09-23 Accepted: 2005-10-26

\begin{abstract}
AIM: To evaluate the functions of a new bioartificial liver (BAL) system in vitro and in vitro.

MEHTODS: The BAL system was configurated by inoculating porcine hepatocyte spheroids into the cell circuit of a hollow fiber bioreactor. In the experiments of $B A L$ in vitro, the levels of alanine aminotransferase (ALT), total bilirubin (TB), and albumin (ALB) in the circulating hepatocyte suspension and RPMI-1640 medium were determined during $6 \mathrm{~h}$ of circulation in the BAL device. In the experiments of BAL in vitro, acute liver failure (ALF) model in canine was induced by an end-side portocaval shunt combined with common bile duct ligation and transaction. Blood ALT, TB and ammonia levels of ALF in canines were determined before and after BAL treatment.
\end{abstract}

RESULTS: During $6 \mathrm{~h}$ of circulation in vitro, there was no significant change of ALT, whereas the TB and ALB levels gradually increased with time both in the hepatocyte suspension and in RPMI-1640 medium. In the BAL treatment group, blood ALT, TB and ammonia levels of ALF in canines decreased significantly.

CONCLUSION: The new BAL system has the ability to perform liver functions and can be used to treat ALF.

(c) 2006 The WJG Press. All rights reserved.

Key words: Bioartificial liver; Liver transplantation; Porcine hepatocyte

Chen Z, Ding YT. Functional evaluation of a new bioartificial liver system in vitro and in vitro. World J Gastroenterol 2006; 12(8): 1312-1316

http://www.wjgnet.com/1007-9327/12/1312.asp

\section{INTRODUCTION}

Acute hepatic failure (ALF) is a disease with a high mortality. Although significant improvements have been achieved in critical care therapy, the mortality rate of ALF patients is about $80 \%$. In many patients liver failure is reversible and if short-term liver support is provided, the liver may regenerate. Survivors may recover full liver function and a normal life expectancy. For many years, liver transplantation has been the only curative treatment for this condition, subjecting many patients to replacement of a potentially self-regenerating organ, with the lifetime danger of immunosuppression and its attendant complications, such as malignancy. Additionally, because of the shortage of livers available for transplantation, many patients die before a transplant can be performed, or are too ill to undergo surgery at the time a liver becomes available. The survival of patients excluded from liver transplantation or those with potentially reversible ALF might be improved with temporary artificial liver support. Among a variety of liver support therapies, bioartificial liver (BAL) therapy is marked as the most promising solution. Some BAL devices are under trials in animals ${ }^{[1-4]}$ and human beings ${ }^{[5-8]}$. The major problem is how to configure a BAL system. To attain enhanced efficacy of liver support, several BAL configurations have been proposed. The long-term maintenance of hepatocyte function is crucial for any BAL system. Some systems use hepatocytes attached to microcarrier beads or multicellular spheroid aggregates ${ }^{[9-11]}$. In regard to bioreactor design, various bioreactor configurations have been proposed that employ glass plates, hollow fiber membranes, encapsulation in biological matrices, and 3-dimensional carrier materials ${ }^{[12-15]}$.

In this study, porcine hepatocytes were isolated by in situ recirculating collagenase perfusion method and cultured with spinner culture method to prepare hepatocyte spheroids. A new BAL system was configured by inoculating hepatocyte spheroids into cell circuit of a BIOLIV A3A hollow fiber bioreactor and the functions of the BAL system were evaluated in vitro as previously described $^{[16,17]}$. At same time, the efficacy evaluation of the 
BAL system was conducted in a model of ALF canines induced by an end-side portocaval shunt combined with common bile duct ligation and transaction.

\section{MATERIALS AND METHODS}

\section{Materials}

Chinese experimental male and female miniature pigs $(n=13)$ weighing $2.5-4.0 \mathrm{~kg}$, were provided by Beijing Agricultural University. The pigs were allowed free access to water and fasted for $12 \mathrm{~h}$ before the experiment. Hybrid male and female $\operatorname{dogs}(n=16)$ weighing $10-15 \mathrm{~kg}$, were provided by the Experimental Animal Center of Drum Tower Hospital. Collagenase IV, RPMI-1640 medium, hepatocyte growth factor, nerve growth factor, and N-2hydroxyethypiperazine-N'-2-ethanesulfonic acid (HEPES) were from Gibco BRL Life Technologies, Grand Island, NY, USA. Insulin, glucagon, transferrin, linoleic acid, glutamine, bovine serum albumin, $\mathrm{Na}_{2} \mathrm{SeO}_{3}, \mathrm{CuSO}_{4} \bullet 5 \mathrm{H}_{2} \mathrm{O}$, $\mathrm{ZnSO}_{4} \bullet 7 \mathrm{H}_{2} \mathrm{O}$, poly (2-hydroxyethyl methacrylate) (polyHEMA), penicillin, and streptomycin were from SigmaAldrich Chemie Gmbh, Steinheim, Germany. BIOLIV A3A hollow fiber cartridges with abnormal molecular weight cut-off of $70 \mathrm{Ka}$, a pore size of $200 \mathrm{~nm}$, and a surface area of $1.06 \mathrm{~m}^{2}$, were provided by Cell Biotech Ltd, Hong Kong, China.

\section{Hepatocyte isolation and culture}

Porcine hepatocytes were isolated by in situ recirculating collagenase perfusion method ${ }^{[18]}$. Hepatocytes were inoculated at a density of $5 \times 10^{7} / \mathrm{mL}$ in serum-free RPMI-1640 medium supplemented with $200 \mu \mathrm{g} / \mathrm{L}$ hydrocortisone, $1 \mathrm{mg} / \mathrm{L}$ hepatocyte growth factor, 10 $\mu \mathrm{g} / \mathrm{L}$ nerve growth insulin, $4 \mu \mathrm{g} / \mathrm{L}$ glucagon, $6.25 \mathrm{mg} / \mathrm{L}$ transferrin, $10 \mathrm{mg} / \mathrm{L}$ linoleic acid, $2 \mathrm{mmol} / \mathrm{L}$ glutamine, 0.5 $\mathrm{g} / \mathrm{L}$ bovine serum albumin, $3 \mathrm{nmol} / \mathrm{L} \mathrm{Na}_{2} \mathrm{SeO}_{3}, 0.1 \mu \mathrm{mol} / \mathrm{L}$ $\mathrm{CuSO}_{4} \bullet 5 \mathrm{H}_{2} \mathrm{O}, 50 \mathrm{pmol} / \mathrm{L} \mathrm{ZnSO}_{4} \bullet 7 \mathrm{H}_{2} \mathrm{O}, 15 \mathrm{mmol} / \mathrm{L}$ N-2hydroxyethylpiperazine-N'-2-ethanesulfonic acid (HEPES), $200 \mathrm{mg} / \mathrm{L}$ cefoperazone sodium, $100000 \mathrm{U} / \mathrm{L}$ penicillin, and $100 \mathrm{mg} / \mathrm{L}$ streptomycin ${ }^{[19]}$. To inhibit cell attachment and induce the formation of cell spheroids in suspension, $250 \mathrm{~mL}$ bottles were coated with poly-HEMA. About 100 $\mathrm{mL}$ of hepatocyte suspension was placed in each bottle. The bottles were placed in an incubator $\left(50 \mathrm{~mL} / \mathrm{L} \mathrm{CO}_{2}\right.$, $\left.37^{\circ} \mathrm{C}\right)$ for $20 \mathrm{~h}$ and slowly rotated $(12$ revolutions/h) as previously described ${ }^{[20,21]}$.

\section{Configuration of BAL system}

The BAL system was configured by inoculating the hepatocyte spheroids into the cell circuit of a hollow fiber bioreactor (BIOLIV A3A, Cell Biotech Limited, HK, China). The total cell circuit volume was $250 \mathrm{~mL}$. Hepatocyte spheroids in serum-free RPMI-1640 medium containing $1.0 \times 10^{10}$ primary porcine hepatocytes were infused into the outer space of the hollow fibers and the medium was circulated at $20 \mathrm{~mL} / \mathrm{min}$ with continuous $\mathrm{O}_{2}$ input $(2 \mathrm{~L} / \mathrm{min}$ ) (Figure 1). The bioreactor was kept at $37.5^{\circ} \mathrm{C}$ in an incubator ${ }^{[1] 6]}$.

\section{Canine ALF model}

Canine ALF model was induced by end-side portocaval

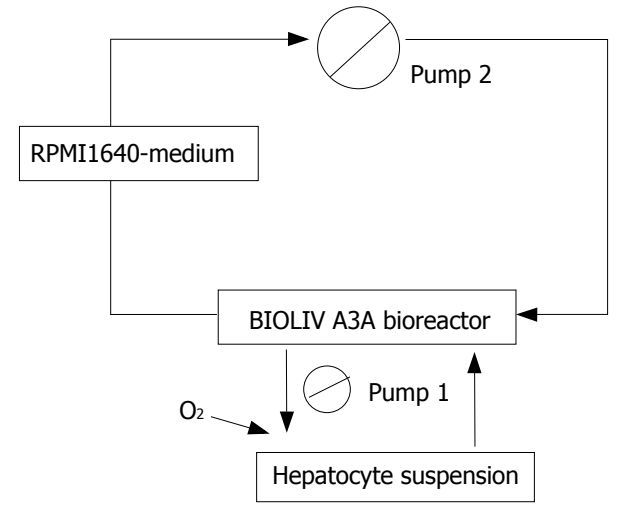

Figure 1 Schematic picture of the BAL system.

shunt combined with common bile duct ligation and transaction as previously described ${ }^{[22]}$. All canines developed ALF $14 \mathrm{~d}$ after operation.

\section{Determination of functions of $B A L$ system in vitro}

Independent experiments were performed 5 times with the BAL device. The RMPI-1640 medium flowed through the lumen of the hollow fibers at a rate of $30 \mathrm{~mL} / \mathrm{min}$. Samples of the hepatocyte suspension and RMPI-1640 medium were obtained at $2 \mathrm{~h}$ intervals during $6 \mathrm{~h}$ of circulation. Changes of alanine aminotransferase (ALT), total bilirubin (TB), and albumin (ALB) levels in the circulating hepatocytes and medium were determined with an automatic biochemical analyzer (Hitachi 7600, Japan).

\section{Determination of functions of BAL system in vivo}

Independent experiments were performed 8 times with the BAL device. Hemoperfusion was performed from femoral artery to femoral vein through the bioreactor at a rate of $30 \mathrm{~mL} / \mathrm{min}$. The ALF model canines were divided into two groups: the BAL treatment group $(n=8)$ consisiting of canine ALF models was perfused using the above serumfree medium inoculated with porcine hepatocyte spheroids for $6 \mathrm{~h}$, and the control group $(n=8)$ consisting of the canine ALF model was perfused using the above serumfree medium without porcine hepatocytes for $6 \mathrm{~h}$.

Blood samples were obtained before (pre-circulation) and after the treatment (post-circulation). Blood ALT and TB were determined with an automatic biochemical analyzer (Hitachi 7600, Japan). Blood ammonia was determined with a biochemical analyzer (DT60II, Johnson and Johnson Medical Ltd., USA).

\section{Statistical analysis}

Results were expressed as mean \pm SD. Statistical differences were evaluated by analysis of variance (ANOVA). $P<0.05$ was considered statistically significant.

\section{RESULTS}

ALT, TB and ALB levels in hepatocyte suspensions and RPMI-1640 media during circulation

The average viability of the isolated hepatocytes was $97 \%$ by trypan blue exclusion. The formation of hepatocyte spheroids was observed after a culture of $20 \mathrm{~h}$. In the hepatocyte suspensions, there were no significant changes of ALT during $6 \mathrm{~h}$ of circulation, whereas the TB and 
Table 1 Changes of ALT, TBi and ALB in hepatocyte suspensions and RPMI-1640 media during circulation (meantSD)

\begin{tabular}{lcccc}
\hline \multirow{2}{*}{ Portion } & \multirow{2}{*}{ Time (h) } & \multicolumn{3}{c}{ Biochemical parameters } \\
\cline { 2 - 5 } & & $\mathbf{A L T}(\mathbf{U} / \mathbf{L})$ & $\mathbf{T B}(\boldsymbol{\mu m o l} / \mathbf{L})$ & $\mathbf{A L B}(\mathbf{g} / \mathbf{L})$ \\
\hline Hepatocyte suspensions $(n=5)$ & 0 & $13.7 \pm 3.5$ & $3.5 \pm 2.4$ & $2.8 \pm 1.5$ \\
& 2 & $15.2 \pm 4.5$ & $5.0 \pm 1.6^{\mathrm{c}}$ & $3.1 \pm 1.6$ \\
& 4 & $17.9 \pm 4.3$ & $6.2 \pm 1.8^{\mathrm{c}}$ & $3.6 \pm 0.9^{\mathrm{c}}$ \\
& 6 & $18.4 \pm 3.2$ & $8.4 \pm 2.6^{\mathrm{c}}$ & $3.8 \pm 1.2^{\mathrm{c}}$ \\
RPMI1640 media $(n=5)$ & 0 & $0.8 \pm 0.2^{\mathrm{a}}$ & $0.0 \pm 0.0^{\mathrm{c}}$ & $0.5 \pm 0.1^{\mathrm{a}}$ \\
& 2 & $1.5 \pm 0.5^{\mathrm{a}}$ & $4.8 \pm 1.3^{\mathrm{c}}$ & $1.8 \pm 0.3^{\mathrm{ac}}$ \\
& 4 & $1.3 \pm 0.3^{\mathrm{a}}$ & $5.7 \pm 1.6^{\mathrm{c}}$ & $2.5 \pm 0.2^{\mathrm{ac}}$ \\
& 6 & $1.4 \pm 1.0^{\mathrm{a}}$ & $6.8 \pm 2.5^{\mathrm{c}}$ & $2.8 \pm 0.3^{\mathrm{ac}}$ \\
\hline
\end{tabular}

${ }^{\text {a }} P<0.05$ vs hepatocyte suspensions at the same circulation time, ${ }^{c} P<0.05$ vs $0 \mathrm{~h}$.

ALB levels increased gradually $(P<0.05)$. The precirculation levels of ALT, TB and ALB were lower in the RPMI-1640 media than in hepatocyte suspensions $(P<0.05)$. During $6 \mathrm{~h}$ of circulation, there was no significant change of ALT, whereas the TB and ALB levels gradually increased $(P<0.05)$. At 2,4 , and $6 \mathrm{~h}$ of circulation, there were no significant differences of $\mathrm{TB}$ levels in RPMI-1640 media and hepatocyte suspensions, but the ALB concentration was lower in RPMI- 1640 media than in hepatocyte suspensions at all times $(P<0.05$, Table 1).

\section{Changes of biochemical parameters in ALF canines after $B A L$ circulation}

The two groups were comparable in terms of body weight $(12.6 \pm 2.2 \mathrm{~kg}$ in BAL group and $13.2 \pm 2.1 \mathrm{~kg}$ in controls) and biochemical parameters before circulation. The parameters after circulation are shown in Table 2. In the BAL treatment group, blood ALT, TB and ammonia levels significantly decreased from $455.1 \pm 225.2 \mathrm{U} / \mathrm{L}$, $74.6 \pm 25.4 \mu \mathrm{mol} / \mathrm{L}$ and $131.2 \pm 28.3 \mu \mathrm{mol} / \mathrm{L}$ before circulation to $273.3 \pm 151.3 \mathrm{U} / \mathrm{L}, 33.1 \pm 11.7 \mu \mathrm{mol} / \mathrm{L}$ and $33.4 \pm 21.7 \mu \mathrm{mol} / \mathrm{L}$ after circulation. While in the control group, there were no significant differences in blood ALT, TB and ammonia levels between pre-circulation and postcirculation, though these indices were declined slightly $(P>0.05)$. Blood ALT, TB and ammonia levels were lower in BAL group than in control group after circulation $(P<0.05)$. The viability of hepatocytes was about $90 \%$ at the end of BAL treatment.

\section{Survival rate of ALF canines}

The survival rates of ALF canines $7 \mathrm{~d}$ after treatment were $100 \%(8 / 8)$ and $62.5 \%(5 / 8)$ in BAL group and control group respectively with no significant difference $(P>0.05)$.

\section{Adverse reaction related to $B A L$ treatment}

The ALF canines had no apparent signs of toxicity during and after BAL treatment.

\section{DISCUSSION}

Treatment of ALF is a formidable clinical challenge. Currently, liver transplantation is the most effective therapy. Although advances have been achieved in
Table 2 Changes of biochemical parameters before and after circulation in two groups (mean \pm SD)

\begin{tabular}{lccc}
\hline \multirow{2}{*}{ Group } & \multicolumn{3}{c}{ Biochemical parameters } \\
\cline { 2 - 4 } & $\mathbf{A L T}(\mathbf{U} / \mathbf{L})$ & $\mathbf{T B}(\mu \mathbf{m o l} / \mathbf{L})$ & $\mathbf{N H 3}(\mu \mathbf{m o l} / \mathbf{L})$ \\
\hline BAL group $(n=8)$ & & & \\
Pre-model & $18.2 \pm 12.6$ & $2.8 \pm 1.2$ & $1.0 \pm 0.0$ \\
Pre-circulation & $325.8 \pm 54.7^{\mathrm{c}}$ & $72.6 \pm 23.5^{\mathrm{c}}$ & $132.2 \pm 28.3^{\mathrm{c}}$ \\
Post-circulation & $212.3 \pm 42.3^{\mathrm{ac}}$ & $33.4 \pm 22.2^{\mathrm{ac}^{\mathrm{c}}}$ & $33.2 \pm 21.7^{\mathrm{ac}}$ \\
Control group $(n=8)$ & & & \\
$\quad$ Pre-model & $16.6 \pm 38.3$ & $2.6 \pm 1.9$ & $1.0 \pm 0.0$ \\
Pre-circulation & $300.2 \pm 52.6^{\mathrm{c}}$ & $74.3 \pm 23.7^{\mathrm{c}}$ & $126.3 \pm 30.4^{\mathrm{c}}$ \\
Post-circulation & $280.1 \pm 45.9^{\mathrm{c}}$ & $65.5 \pm 35.6^{\mathrm{c}}$ & $100.3 \pm 13.5^{\mathrm{c}}$ \\
\hline
\end{tabular}

${ }^{\mathrm{a}} \mathrm{P}<0.05$ vs pre-circulation, ${ }^{\mathrm{c}} \mathrm{P}<0.05$ vs pre-model.

transplantation techniques, donor organ shortage remains a serious problem. The mortality of ALF is still high. However, many ALF patients can recover through liver regeneration after short-term liver support, which has prompted the design of an extracorporeal liver support device to "bridge" patients over until they either recover or receive a liver transplant. Among these devices, the BAL system is most promising. Various types of hepatocytes are inserted and different device designs have been proposed [23-25]. The BAL system differs from non-biologic artificial liver devices in the synthesis of essential metabolites and the selective removal of toxic substances, which are carried out by the cultured hepatocytes. An ideal BAL system can provide all the hepatic functions.

In this study, we configurated a new BAL system by inoculating porcine hepatocyte spheroids into the cell circuit of a hollow fiber bioreactor and evaluated its functions in vitro and in vivo.

Nagaki et $a l^{[26]}$ demonstrated that primary hepatocytes are superior to transformed hepatocytes as a source of biotransformation functions in the BAL system. The BAL system we developed uses viable porcine hepatocytes in the bioreactor to exert liver functions.

Since $10-30 \%$ of hepatocytes in the normal human liver are needed to maintain normal hepatic functions ${ }^{[27]}$, Matsmura et al ${ }^{[28]}$ proposed that a BAL requires $150-450 \mathrm{~g}$ of liver. Our BAL device contains $1.0 \times 10^{10}$ hepatocytes to meet the need of patients with ALF. The liver of an adult canine weighs about $335 \mathrm{~kg}$ and contains $3.35 \times 10^{9}$ hepatocytes. Therefore, the BAL device could be used in this experiment.

It has been reported that cell-cell interaction has an important role in maintaining the viability and the functions of hepatocytes ${ }^{[29]}$. In the present study, hepatocytes were incubated in serum-free medium and poly-HEMA-coated bottles by a continuous rotational method in order to restrict their attachment to the wall and promote the formation of hepatocyte spheroids. This method could not only facilitate cell-cell interaction and maintain cell functions, but it also meet the requirement of high-density culture in $\mathrm{BA}$, thus reducing the possibility of immunoreaction by using serum-free medium with hormone and various growth factors ${ }^{[19]}$.

The ideal bioreactor should provide a good environment for growth and metabolism of hepatocytes 
as well as the efficient exchange of substances. At present, the most commonly used device is a hollow fiber bioreactor with many small hollow fibers made from semipermeable membranes. The device has two independent compartments that are separated by hollow fiber semipermeable membranes. The intratubular space is used to perfuse blood, while the extratubular space is used to culture hepatocytes. The blood or plasma of patients flows into the bioreactor, exchanging substances with hepatocytes through the semipermeable membranes. The membranes also provide immuno-isolation. In view of the molecular weight of albumin ( $68 \mathrm{ku})$, a hollow fiber membrane with $200 \mathrm{~nm}$ pore size and a MWCO of $70 \mathrm{ku}$ was chosen for this study. The membrane allows passage of some relatively small molecules such as albumin, but restricts the passage of lymph cells and high molecular weight proteins. Blood-borne toxins and metabolic precursors are free to diffuse across the membrane to hepatocytes where they are metabolized. Metabolic products and detoxified toxins are free to diffuse back across the membrane to the flowing blood. Hepatocytes in the bioreactor also synthesize molecules (proteins, coagulation factors, enzymes, carrier molecules) that pass across the hollow fiber cartridge into blood. Continuous $\mathrm{O}_{2}$ input could ensure hepatocytes to gain sufficient oxygen. Therefore, our BAL device has such a novelty as it uses hepatocyte spheroids and serum-free medium compared to previously reported BAL ${ }^{[13-16]}$.

Experiments of BAL in vitro showed that $\mathrm{TB}$ and ALB levels in hepatocyte suspensions and in RPMI-1640 media increased during $6 \mathrm{~h}$ of circulation. There were no significant differences of TB levels in RPMI-1640 medium and hepatocytes suspensions after $2 \mathrm{~h}$ of circulation. ALB level was lower in RPMI-1640 samples than in hepatocyte suspensions at all periods of circulation. ALB levels in RPMI-1640 medium and hepatocyte suspension averaged $2.8 \mathrm{~g} / \mathrm{L}$ and $3.8 \mathrm{~g} / \mathrm{L}$, respectively, after $6 \mathrm{~h}$ of circulation. During the $6 \mathrm{~h}$ of circulation, there were no significant changes of ALT levels in RPMI-1640 medium or hepatocyte suspensions. ALT level was lower in RPMI-1640 medium than in hepatocyte suspensions at all time points. Bilirubin and albumin could readily cross the semi-permeable membrane because of their low molecular weights. The results indicate that albumin synthesized by hepatocytes in the BAL system can cross into the circulating stream in the intratubular space of hollow fibers.

In the experiments of BAL in vivo, blood ALT, TBi and ammonia levels significantly decreased after $6 \mathrm{~h}$ of circulation in the BAL group. There were no significant differences in blood ALT, TB and ammonia between pre-circulation and post-circulation in the control group, though these indices were slightly decreased after circulation. These results suggest that our BAL system has the potential not only to protect against hepatocyte destruction but also to dilute excess ALT in the systemic serum, which is consistent with the previous report ${ }^{[30]}$. The survival rate was higher in BAL group than in control group, but there was no statistical significance, which may be related to the quantity of the samples. The viability of hepatocytes was about $90 \%$ at the end of BAL treatment, indicating that our BAL device has its advantages.

In conclusion, the new BAL system configurated in this research has a certain liver support effect and appears to have potential advantages for its clinical use in patients with ALF.

\section{REFERENCES}

1 Frühauf NR, Oldhafer KJ, Höltje M, Kaiser GM, Frühauf JH, Stavrou GA, Bader A, Broelsch CE. A bioartificial liver support system using primary hepatocytes: a preclinical study in a new porcine hepatectomy model. Surgery 2004; 136: 47-56

2 Yamashita Y, Shimada M, Tsujita E, Shirabe K, Ijima H, Nakazawa K, Sakiyama R, Fukuda J, Funatsu K, Sugimachi K. Efficacy of a larger version of the hybrid artificial liver support system using a polyurethane foam/spheroid packed-bed module in a warm ischemic liver failure pig model for preclinical experiments. Cell Transplant 2003; 12: 101-107

3 Mizumoto H, Funatsu K. Liver regeneration using a hybrid artificial liver support system. Artif Organs 2004; 28: 53-57

4 Shito M, Tilles AW, Tompkins RG, Yarmush ML, Toner M. Efficacy of an extracorporeal flat-plate bioartificial liver in treating fulminant hepatic failure. J Surg Res 2003; 111: 53-62

5 Demetriou AA, Brown RS Jr, Busuttil RW, Fair J, McGuire BM, Rosenthal P, Am Esch JS 2nd, Lerut J, Nyberg SL, Salizzoni M, Fagan EA, de Hemptinne B, Broelsch CE, Muraca M, Salmeron JM, Rabkin JM, Metselaar HJ, Pratt D, De La Mata M, McChesney LP, Everson GT, Lavin PT, Stevens AC, Pitkin Z, Solomon BA. Prospective, randomized, multicenter, controlled trial of a bioartificial liver in treating acute liver failure. Ann Surg 2004; 239: 660-667; discussion 667-670

6 Patzer II JF, Lopez RC, Zhu Y, Wang ZF, Mazariegos GV, Fung JJ. Bioartificial liver assist devices in support of patients with liver failure. Hepatobiliary Pancreat Dis Int 2002; 1: 18-25

7 van de Kerkhove MP, Di Florio E, Scuderi V, Mancini A, Belli A, Bracco A, Scala D, Scala S, Zeuli L, Di Nicuolo G, Amoroso $\mathrm{P}$, Calise F, Chamuleau RA. Bridging a patient with acute liver failure to liver transplantation by the AMC-bioartificial liver. Cell Transplant 2003; 12: 563-568

8 Sauer IM, Kardassis D, Zeillinger K, Pascher A, Gruenwald A, Pless G, Irgang M, Kraemer M, Puhl G, Frank J, Müller AR, Steinmüller T, Denner J, Neuhaus P, Gerlach JC. Clinical extracorporeal hybrid liver support-phase I study with primary porcine liver cells. Xenotransplantation 2003; 10: 460-469

9 Nyberg SL, Hardin J, Amiot B, Argikar UA, Remmel RP, Rinaldo P. Rapid, large-scale formation of porcine hepatocyte spheroids in a novel spheroid reservoir bioartificial liver. Liver Transpl 2005; 11: 901-910

10 McLaughlin BE, Tosone CM, Custer LM, Mullon C. Overview of extracorporeal liver support systems and clinical results. Ann N Y Acad Sci 1999; 875: 310-325

11 Pahernik SA, Thasler WE, Doser M, Gomez-Lechon MJ, Castell MJ, Planck H, Koebe HG. High density culturing of porcine hepatocytes immobilized on nonwoven polyurethanebased biomatrices. Cells Tissues Organs 2001; 168: 170-177

12 Kobayashi N, Okitsu T, Maruyama M, Totsugawa T, Kosaka Y, Hayashi N, Nakaji S, Tanaka N. Development of a cellulosebased microcarrier containing cellular adhesive peptides for a bioartificial liver. Transplant Proc 2003; 35: 443-444

13 Gerlach JC, Zeilinger K, Sauer IM, Mieder T, Naumann G, Grünwald A, Pless G, Holland G, Mas A, Vienken J, Neuhaus P. Extracorporeal liver support: porcine or human cell based systems? Int J Artif Organs 2002; 25: 1013-1018

14 van de Kerkhove MP, Di Florio E, Scuderi V, Mancini A, Belli A, Bracco A, Dauri M, Tisone G, Di Nicuolo G, Amoroso P, Spadari A, Lombardi G, Hoekstra R, Calise F, Chamuleau RA. Phase I clinical trial with the AMC-bioartificial liver. Int J Artif Organs 2002; 25: 950-959

15 Kuddus R, Patzer JF 2nd, Lopez R, Mazariegos GV, Meighen B, 
Kramer DJ, Rao AS. Clinical and laboratory evaluation of the safety of a bioartificial liver assist device for potential transmission of porcine endogenous retrovirus. Transplantation 2002; 73: 420-429

16 Xue YL, Zhao SF, Zhang ZY, Wang YF, Li XJ, Huang XQ, Luo $Y$, Huang YC, Liu CG. Effects of a bioartificial liver support system on acetaminophen induced acute liver failure canines. World J Gastroenterol 1999; 5: 308-311

17 Gan JH, Zhou XQ, Qin AL, Luo EP, Zhao WF, Yu H, Xu J. Hybrid artificial liver support system for treatment of severe liver failure. World J Gastroenterol 2005; 11: 890-894

18 Chen Z, Ding Y, Zhang H. Cryopreservation of suckling pig hepatocytes. Ann Clin Lab Sci 2001; 31: 391-398

19 Chen Z, Ding Y, Zhang H. Morphology, viability and functions of suckling pig hepatocytes cultured in serum-free medium at high density. Dig Surg 2002; 19: 184-191

20 Matsushita T, Amiot B, Hardin J, Platt JL, Nyberg SL. Membrane pore size impacts performance of a xenogeneic bioartificial liver. Transplantation 2003; 76: 1299-1305

21 Koide N, Sakaguchi K, Koide Y, Asano K, Kawaguchi M, Matsushima H, Takenami T, Shinji T, Mori M, Tsuji T. Formation of multicellular spheroids composed of adult rat hepatocytes in dishes with positively charged surfaces and under other nonadherent environments. Exp Cell Res 1990; 186: 227-235

22 Awad SS, Hemmila MR, Soldes OS, Sawada S, Rich PB, Mahler S, Gargulinski M, Hirschl RB, Bartlett RH. A novel stable reproducible model of hepatic failure in canines. J Surg Res 2000; 94: 167-171

23 Li J, Li LJ, Cao HC, Sheng GP, Yu HY, Xu W, Sheng JF. Establishment of highly differentiated immortalized human hepa- tocyte line with simian virus 40 large tumor antigen for liver based cell therapy. ASAIO J 2005; 51: 262-268

24 David B, Dufresne M, Nagel MD, Legallais C. In vitro assessment of encapsulated C3A hepatocytes functions in a fluidized bed bioreactor. Biotechnol Prog 2004; 20: 1204-1212

25 van de Kerkhove MP, Hoekstra R, Chamuleau RA, van Gulik TM. Clinical application of bioartificial liver support systems. Ann Surg 2004; 240: 216-230

26 Nagaki M, Miki K, Kim YI, Ishiyama H, Hirahara I, Takahashi H, Sugiyama A, Muto Y, Moriwaki H. Development and characterization of a hybrid bioartificial liver using primary hepatocytes entrapped in a basement membrane matrix. Dig Dis Sci 2001; 46: 1046-1056

27 Nagasue N, Yukaya H, Ogawa Y, Kohno H, Nakamura T. Human liver regeneration after major hepatic resection. A study of normal liver and livers with chronic hepatitis and cirrhosis. Ann Surg 1987; 206: 30-39

28 Matsumura KN, Guevara GR, Huston H, Hamilton WL, Rikimaru M, Yamasaki G, Matsumura MS. Hybrid bioartificial liver in hepatic failure: preliminary clinical report. Surgery 1987; 101: 99-103

29 Lazar A, Peshwa MV, Wu FJ, Chi CM, Cerra FB, Hu WS. Formation of porcine hepatocyte spheroids for use in a bioartificial liver. Cell Transplant 1995; 4: 259-268

30 Naruse K, Sakai Y, Lei G, Sakamoto Y, Kobayashi T, Puliatti C, Aronica G, Morale W, Leone F, Qiang S, Ming SG, Ming S, Li Z, Chang SJ, Suzuki M, Makuuchi M. Efficacy of nonwoven fabric bioreactor immobilized with porcine hepatocytes for ex vivo xenogeneic perfusion treatment of liver failure in dogs. Artif Organs 2001; 25: 273-280

S- Editor Guo SY L- Editor Wang XL E- Editor Bi L 